\title{
GENETIC DIVERGENCE OF LOWLAND RICE (ORYZA SATIVA L.) GENOTYPES IN UGANDA
}

\author{
Zelalem ZEWDU',2* \\ ${ }^{1}$ Makerere University, School of Agricultural Sciences, P.O.Box 7062, Kampala, Uganda \\ ${ }^{2}$ Ethiopian Institute of Agricultural Research, Fogera National Rice Research and Training Center, Woreta, Ethiopia
}

\begin{abstract}
Forty-eight lowland rice genotypes with two checks were evaluated for agronomic performance, genetic variability, heritability, and genetic advance for yield and yield contributing traits. Genotypes SR33859-HB3324-133 (45.7 qha-1), SR33859HB3324-93 (40.2 qha-1) were the high yielding genotypes above the better check. The analysis of variance showed significant differences for all measured traits and indicating the presence of high genetic variability among genotypes. A highly significant $(\mathrm{P} \leq 0.001)$ correlations were observed between flag leaf length and plant height ( $\mathrm{rp}=0.76$ and $\mathrm{rg}=0.84)$, panicle length and plant height ( $\mathrm{rp}=0.77, \mathrm{rg}=0.90$ ), and panicle length and flag leaf length ( $\mathrm{rp}=0.75$ and $\mathrm{rg}=0.89$ ). The estimates of GCV were lower than the respective PCV for all traits, indicating the influence of environmental factors on the expression of the traits. Characters like grain yield ( $94 \%$ and 90.9), flag leaf length (97\% and 71.6), number of effective tillers per hill (91\% and 67.2) and plant height (99.0 \% and 50.7) showed high heritability coupled with moderate genetic advance as percent of the mean, which suggesting that these traits are controlled by the additive type of gene action and selection could be possible for the improvement of these characters. Moderate heritability estimates with low genetic advance as percent of the mean were recorded for flag leaf width and number of days to maturity indicated the presence of non-additive gene effects, and selection for these traits would be poor. As a result, the variability that exists in the germplasm provides an opportunity to use these genotypes in the genetic improvement program.
\end{abstract}

Keywords: Rice, Variability, GCV, PCV, Heritability, Genetic advance

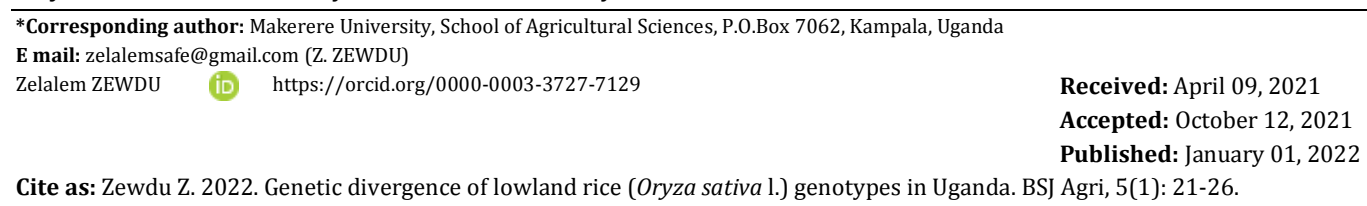

\section{Introduction}

Rice (Oryza sativa L.) is most commonly produced in Asia, Africa, and Australia (Dogara and Jumare, 2014). It is the third most cultivated cereal crop in the world, after wheat and maize (FAO, 2018). Rice production in Uganda started in 1942, mainly to feed the World War II soldiers. However, due to a number of constraints, production remained minimal until 1974 . Today rice is grown mainly by small-scale farmers almost throughout the country, but also by large-scale farmers in few places (Kijima, 2012). Most of the rice production in Uganda is in the Eastern parts of the country, followed by the Western part of Uganda. According to Dewina et al., (2010) rice accounted for $0.42 \%$ of the total production of food crops in Uganda and ranking fifth after maize, cassava, bananas, and beans.

Paddy rice production in Uganda ranged from 72,000 to 97,505 hectares with a total yield of 109 to 262,631 thousand tonnes respectively from 2000 to 2017 (FAO, 2018). Since the introduction of upland rice in 2002, farmers producing rice in Uganda increased from 4,000 then to over 35,000 in 2012 (Kijima and Sserunkuuma,2006). Even though the production of rice in the country is increasing in terms of the area while the national productivity of the crop doesn't exceed 2.81 tonnes per hectare. According to Akongo, (2017), rice production in the country is constrained by variability in climate, poor market prices, weed infestation, poor seed variety, bird damage, limited knowledge, and declining soil fertility.

Creating genetic variability either by crossing and/or introduction would be one of the solutions to increase the chance of selection and success in the breeding program. Genetic improvement of any crop mainly depends upon the amount of genetic variability present in the population. The success of breeding depends on the extent and the magnitude of variability existing in the germplasm, the heritability of the traits, and information on the genetic variability, and degree of transmission of the target traits. The variability available in the population can be partitioned into heritable and nonheritable component viz., phenotypic and genotypic coefficients of variation, heritability, and genetic advance on which selection can be effectively carried out.

Heritability is the degree of correspondence between the phenotype and the breeding value of an individual for a particular trait which enables the breeders to select the elite variety for a character. However, heritability indicates only the effectiveness with which selection of a genotype can be based on phenotypic performance but it 


\section{Black Sea Journal of Agriculture}

fails to indicate the expected genetic progress in one cycle of selection. According to Johnson et al., (1955), high heritability alone is not enough to make an efficient selection, unless the information is accompanied by for substantial amount of genetic advance. As a result, the present investigation was undertaken to assess the agronomic performance, the nature, and magnitude of genetic variability, heritability, and genetic advance among the genotypes for further utilization in breeding programs.

\section{Material and Methods}

A field experiment was conducted at the National Crops Resources Research Institute (NaCRRI) in Kampala, Uganda in the two cropping seasons of 2015 (referred to as seasons $2015 \mathrm{~A}$ and $2015 \mathrm{~B}$ ) with the objective of evaluating the genetic variability of KAFACI materials for yield and yield related traits. NaCRRI is located at $0^{\circ} 31^{\prime}$ $\mathrm{N}, 32^{\circ} 35^{\prime} \mathrm{E}$, with a mean altitude of 1150 meters above sea level. The soils are ferralitic (red sandy and clay loam) and have a pH range of 4.9 - 5.0. The average annual rainfall is $1300 \mathrm{~mm}$ and maximum and minimum temperature of $28.5{ }^{\circ} \mathrm{C}$, and $13.0^{\circ} \mathrm{C}$, respectively. List of genotypes used for the study are presented in Table 1.

A nursery was raised for each genotype and twenty-one days old seedlings of forty-eight genotypes were transplanted in the swamp field in a 6 by 8 alpha lattice design with two replications. The spacing was $20 \mathrm{~cm}$ between rows and between plants and $40 \mathrm{~cm}$ between plots and between blocks with 1 meter between replications. Each treatment was transplanted in plot size of $1.6 \mathrm{~m}$ length and $1 \mathrm{~m}$ wide. The fertilizers, Diammonium Phosphate (DAP) (18-46-0) at a rate of $0.96 \mathrm{~kg}$ and urea (46-0-0) $1.7 \mathrm{~kg} /$ experimental area were used. Half of the Urea and the DAP fertilizer were applied during transplanting. The remaining half urea fertilizer was applied four weeks after transplanting as top dressing to all plots. Weeding and other cultural practices were conducted as needed.

Table1. List of genotypes used for the study

\begin{tabular}{lcccccccc}
\hline & Designation & & Code & Designation & Code & & Designation & Code \\
\hline 1 & SR33859-HB3324-75 & 17 & G1 & SR33701-HB3330-73 & G17 & 33 & SR34042-HB3368-196 & G33 \\
2 & SR33859-HB3324-80 & 18 & G2 & SR33701-HB3330-78 & G18 & 34 & SR34042-HB3368-228 & G34 \\
3 & SR33859-HB3324-93 & 19 & G3 & SR33701-HB3330-86 & G19 & 35 & SR34034F3-125 & G35 \\
4 & SR33859-HB3324-108 & 20 & G4 & SR33701-HB3330-90 & G20 & 36 & SR34034F3-135 & G36 \\
5 & SR33859-HB3324-133 & 21 & G5 & SR33701-HB3330-95 & G21 & 37 & SR34034F3-147 & G37 \\
6 & SR33859-HB3324-142 & 22 & G6 & SR34461-HB3369-54 & G22 & 38 & SR34035F3-57 & G38 \\
7 & SR33686-HB3326-2 & 23 & G7 & SR34461-HB3369-65 & G23 & 39 & SR34035F3-182 & G39 \\
8 & SR33686-HB3326-8 & 24 & G8 & SR34461-HB3369-67 & G24 & 40 & SR34038F3-13 & G40 \\
9 & SR33686-HB3326-12 & 25 & G9 & SR34461-HB3369-105 & G25 & 41 & SR34038F3-32 & G41 \\
10 & SR33686-HB3326-37 & 26 & G10 & SR34461-HB3369-108 & G26 & 42 & SR34038F3-42 & G42 \\
11 & SR33698-HB3329-66 & 27 & G11 & SR34461-HB3369-118 & G27 & 43 & SR34038F3-75 & G43 \\
12 & SR33698-HB3329-70 & 28 & G12 & SR34462-HB3370-64 & G28 & 44 & SR34040F3-29 & G44 \\
13 & SR33701-HB3330-35 & 29 & G13 & SR34461-HB3369-120 & G29 & 45 & SR34042F3-3 & G45 \\
14 & SR33701-HB3330-44 & 30 & G14 & SR34461-HB3369-139 & G30 & 46 & SR34566-7 & G46 \\
15 & SR33701-HB3330-56 & 31 & G15 & SR34042-HB3368-170 & G31 & 47 & NERICA-1 & G47 \\
16 & SR33701-HB3330-71 & 32 & G16 & SR34042-HB3368-182 & G32 & 48 & IR-64 & G48 \\
\hline
\end{tabular}

Data collection was done according to the standard evaluation system for rice described by (IRRI, 2014). Data were collected on five randomly selected and tagged plants for number of effective tillers per hill, plant height $(\mathrm{cm})$, flag leaf length, flag leaf width, panicle length $(\mathrm{cm})$ while, number of days to heading, number of days to maturity and grain yield (kg ha-1) were recorded on plot basis.

The data collected on above mentioned traits were subjected to alpha lattice restricted maximum likelihood (ReML) analysis in GenStat $12^{\text {th }}$ edition software package (Payne et al., 2009). The genotypes were considered a fixed effect while blocks, replications and season were random effects. Means of significant treatments effects were separated using LSD at $\mathrm{P} \leq 0.05$ level of significance. Correlation analysis was done to determine the relationship among different traits included in the study. The linear model for the across season analysis was as follows (equation 1);

$y_{i j k}=u+s_{i}+g_{j}+r / b_{i k}+(s \times g)_{i j}+e_{i j k}$

Where, $y_{i j k}=$ observed value from each experimental unit, $u=$ mean, $s_{i}=$ effect of the $i^{\text {th }}$ season, $g_{j}=$ effect of $j^{\text {th }}$ genotype, $r / b_{i k}=$ effect of replication nested within the $\mathrm{k}^{\text {th }}$ block, $(\mathrm{s} \times \mathrm{g})_{\mathrm{ij}}=$ interaction effect of $\mathrm{j}^{\text {th }}$ genotype and the $\mathrm{i}^{\text {th }}$ season and $\mathrm{e}_{\mathrm{ijk}}=$ the experimental error. 
In addition to these, phenotypic, genotypic variance were estimated and genetic parameters like genotypic coefficient of variation (GCV), phenotypic coefficient of variation (PCV) and heritability in broad sense and genetic advance as percent of mean were calculated as follows. The variance components obtained from the across season analysis result were calculated as (equation 2);

$\mathrm{V}_{\mathrm{ph}}=\mathrm{V}_{\mathrm{G}}+\mathrm{V}_{\mathrm{gs}} / \mathrm{r}+\mathrm{V}_{\mathrm{e}} / \mathrm{rs}$

Where, $r$ and $s$ are the number of replications and seasons respectively.

The phenotypic (PCV) and genotypic (GCV) coefficients of variation were obtained as the ratio of the respective phenotypic $\left(\sqrt{V_{p h}}\right)$ and the genotypic $\left(\sqrt{V_{G}}\right)$ standard deviations to the trait means. Broad sense heritability $(\mathrm{H})$ was estimated as the percentage of the genotypic to the phenotypic variance $\left(\mathrm{V}_{\mathrm{G}} / \mathrm{V}_{\mathrm{ph}}\right)$. The genetic advance (GA) and genetic advance as percent of the mean (GAM) expected from selection of the best $5 \%$ of the genotypes were calculated as (equation 3);
$\mathrm{GA}=\mathrm{K} *\left(\sqrt{ } \mathrm{V}_{\mathrm{ph}}\right) * \mathrm{H}$ and $\left.\mathrm{GAM}=\mathrm{GA} / \mathrm{x}\right) * 100$

Where, GA= genetic advance; $\mathrm{H}=$ heritability; $\mathrm{GAM}=$ genetic advance as percent of the mean; $\mathrm{K}=$ selection intensity of $5 \%=2.06$ and $\sqrt{V_{p h}}=$ phenotypic standard deviation.

\section{Results and Discussion}

\subsection{Analysis of Variance}

The analysis of variance across seasons revealed highly significant differences $(\mathrm{P} \leq 0.001)$ among genotypes for number of effective tillers per hill, number of days to 50 $\%$ heading, number of heading to maturity, panicle length and grain yield while significant at $(\mathrm{P} \leq 0.01)$ for flag leaf length and flag leaf width (Table 2). Genotype-by-season interaction effect was significant $(\mathrm{P} \leq 0.001)$ for number of days to maturity and plant height and significant difference $(\mathrm{P} \leq 0.01)$ for grain yield. There were no significant interactions among genotypes and seasons for effective tiller numbers per hill, number of days to heading, flag leaf length, flag leaf width and panicle length.

Table 2. Combined analysis of variance for grain yield and agronomic traits of 48 lowland rice genotypes evaluated in 2015 A and B cropping seasons at NaCRRI

\begin{tabular}{|c|c|c|c|c|c|c|c|c|c|}
\hline & $\mathrm{df}$ & TL & $\mathrm{DH}$ & DM & $\mathrm{PH}$ & FLL & FLW & PL & GY \\
\hline Rep & 1 & 3.33ns & $21.33^{*}$ & $8.76 \mathrm{~ns}$ & $299.90^{* * *}$ & $57.54 * * *$ & $0.021^{* * *}$ & $4.29 \mathrm{~ns}$ & $25.89 \mathrm{~ns}$ \\
\hline Rep/block & 14 & $10.91^{* *}$ & $37.81^{* * *}$ & $5.87 \mathrm{~ns}$ & $74.64^{* * *}$ & $10.69^{* *}$ & $0.044^{* *}$ & $2.48 \mathrm{~ns}$ & $54.05^{* * *}$ \\
\hline Genotypes (G) & 47 & $35.26^{* * *}$ & $153.38^{* * *}$ & $33.83^{* * *}$ & $421.06^{* * *}$ & $54.42^{* *}$ & $0.063^{* *}$ & $10.70^{* * *}$ & $176.01^{* * *}$ \\
\hline Year $(Y)$ & 1 & 2.96ns & $13.31 \mathrm{~ns}$ & $11.45 \mathrm{~ns}$ & $6.90 \mathrm{~ns}$ & $19.35^{* *}$ & $0.962^{* *}$ & $8.07^{* *}$ & $175.14^{* * *}$ \\
\hline $\mathrm{G}^{*} \mathrm{Y}$ & 47 & $4.28 \mathrm{~ns}$ & $2.02 \mathrm{~ns}$ & $21.74^{* * *}$ & $3.96^{* * *}$ & $1.01 \mathrm{~ns}$ & $0.052 \mathrm{~ns}$ & $0.72 \mathrm{~ns}$ & $16.15^{* *}$ \\
\hline Residual & 81 & 5.61 & 4.4 & 5.57 & 17.06 & 4.34 & 0.011 & 1.55 & 8.26 \\
\hline Total & 191 & 12.94 & 43.06 & 16.57 & 118.9 & 16.67 & 0.040 & 3.71 & 55.80 \\
\hline Mean & & 17.09 & 81.30 & 113.47 & 82.77 & 20.90 & 1.47 & 18.33 & 29.18 \\
\hline $\mathrm{CV}$ & & 13.86 & 2.58 & 2.08 & 4.99 & 9.97 & 7.14 & 6.79 & 9.85 \\
\hline LSD (5\%) & & 4.73 & 2.96 & 3.33 & 5.82 & 4.16 & 0.17 & 2.48 & 5.74 \\
\hline
\end{tabular}

\subsection{Agronomic Performance of Rice Genotypes}

The mean values of genotypes evaluated across seasons under field conditions for agronomic traits is presented in Table 3. The lowest number of effective tillers per hill were found on genotypes G47 (11.6) and G24 (12.9), while the highest number of effective tillers was found on G3 (24.4) and G12 (24.1), the overall mean being 17.1 effective tillers per hill. With an overall mean of 81 days until heading, the earliest heading genotypes were G21 (70 days) and G6 and G9 (71 days), and while genotypes G40 (96 days) was late flowering. In measuring number of days to maturity, the overall mean of 113 days, genotypes G16 (106) followed by G47 (107) days were mature early while genotypes G1 ang G36 took long to mature (120) days.

There was a difference among genotypes in plant height with an overall mean of $82.8 \mathrm{~cm}$. Genotypes G27 (106.9 $\mathrm{cm})$ and genotype G48 $(105.3 \mathrm{~cm})$ were tallest while genotypes G23 $(58.9 \mathrm{~cm})$ and G47 $(65.7 \mathrm{~cm})$ were the shortest. Genotypes showed long flag leaf were G37 (29.2 $\mathrm{cm})$ and G27 $(28.6 \mathrm{~cm})$ and shortest flag leaf was recorded on G47 $(15.1 \mathrm{~cm})$ with mean of $20.9 \mathrm{~cm}$. On the other hand, G2 and G21 gave the shortest flag leaf width $(1 \mathrm{~cm})$ while $\mathrm{G} 29$ was $1.6 \mathrm{~cm}$.

The average panicle length was $18.3 \mathrm{~cm}$, with the longest panicles recorded on genotypes G27 $(22.4 \mathrm{~cm})$ and G1 and G37 $(21.6 \mathrm{~cm})$. Genotypes G9 and G23 $(17.5 \mathrm{~cm})$ and G28 $(16.0 \mathrm{~cm})$ had short panicles. An overall mean of 29.2 qha $^{-1}$ for yield with variation among genotypes, the highest yield was recorded on genotypes, G5 (45.7 $\mathrm{qha}^{-1}$ ), G3 (40.2 qha-1), G44 (39.1 qha-1). The genotypes with the lowest yield included G3 (17.8 $\mathrm{qha}^{-1}$ ), followed by G33 (18.8 qha $\left.^{-1}\right)$.

Genotypic and Phenotypic associations among measured traits

Phenotypic and genotypic correlation of across-season evaluation of the introduced rice genotypes for grain yield and other agronomic traits in field conditions is presented in Table 4. The results showed a moderate positive significant $(\mathrm{P} \leq 0.001)$ correlation between 


\section{Black Sea Journal of Agriculture}

number of effective tillers per hill and grain yield $(\mathrm{rp}=0.47$ and $\mathrm{rg}=0.58)$, number of days to maturity and flag leaf length ( $r p=0.49, \mathrm{rg}=0.0 .73$ ), flag leaf length and number of days to heading ( $\mathrm{rp}$ and $\mathrm{rg}=0.43$ ) and flag leaf width and number of days to heading ( $\mathrm{rp}=0.49, \mathrm{rg}=0.97$ ). A highly significant $(\mathrm{P} \leq 0.001)$ correlations were observed between flag leaf length and plant height ( $\mathrm{rp}=$ $0.76, \mathrm{rg}=0.84$ ), panicle length and plant height ( $\mathrm{rp}=0.77$, $\mathrm{rg}=0.90$ ), and panicle length and flag leaf length ( $\mathrm{rp}=$ 0.75, rg=0.89). Suwansa et al. (2017), Seyoum et al.
(2012) and Sravan et al. (2012) had also reported that flag leaf length, number of panicles per plant and number of spikelets per panicle had significant positive phenotypic coefficients affecting grain yield per plant. On the other hand, a low non-significant negative correlation was observed between number of days to heading and grain yield ( $\mathrm{rp}=-0.13, \mathrm{rg}=-0.07$ ). Suwansa et al. (2017), also reported similar findings that days to flowering had a significant negative phenotypic correlation with grain yield.

Table 3. The mean performance of the genotypes across two seasons

\begin{tabular}{|c|c|c|c|c|c|c|c|c|c|}
\hline Code & $\mathrm{TL}$ & $\mathrm{DH}$ & $\mathrm{DM}$ & $\mathrm{PH}$ & FLL & FLW & PL & $\mathrm{PB}$ & GY \\
\hline G1 & 17.7 & 86 & 120 & 99.3 & 28.4 & 1.5 & 21.6 & 17.1 & 23.2 \\
\hline G2 & 15.4 & 72 & 113 & 68.2 & 17.6 & 1.0 & 18.1 & 20.8 & 25.5 \\
\hline G3 & 24.4 & 80 & 113 & 84.9 & 18.3 & 1.1 & 16.8 & 15.3 & 40.2 \\
\hline G4 & 17.7 & 73 & 111 & 76.5 & 17.0 & 1.1 & 18.9 & 28.7 & 33.2 \\
\hline G5 & 15.8 & 78 & 112 & 80.1 & 19.4 & 1.3 & 19.2 & 13.8 & 45.7 \\
\hline G6 & 14.4 & 71 & 108 & 79.3 & 18.2 & 1.1 & 17.2 & 18.7 & 33.4 \\
\hline G7 & 18.1 & 77 & 112 & 80.1 & 21.1 & 1.1 & 17.7 & 9.2 & 34.0 \\
\hline G8 & 15.1 & 75 & 112 & 79.0 & 16.6 & 1.2 & 17.1 & 24.8 & 23.6 \\
\hline G9 & 20.5 & 71 & 111 & 72.5 & 16.6 & 1.1 & 15.7 & 12.1 & 33.0 \\
\hline G10 & 18.0 & 80 & 114 & 80.3 & 22.1 & 1.2 & 19.6 & 21.9 & 34.6 \\
\hline G11 & 18.0 & 77 & 118 & 79.7 & 19.7 & 1.3 & 18.1 & 18.1 & 37.2 \\
\hline G12 & 24.1 & 84 & 114 & 85.6 & 24.2 & 1.2 & 19.6 & 11.2 & 35.8 \\
\hline G13 & 19.5 & 83 & 113 & 91.8 & 22.3 & 1.3 & 19.6 & 19.1 & 36.1 \\
\hline G14 & 15.5 & 75 & 110 & 76.4 & 17.1 & 1.2 & 17.1 & 17.9 & 32.0 \\
\hline G15 & 15.0 & 81 & 113 & 72.4 & 18.5 & 1.2 & 17.4 & 16.7 & 31.2 \\
\hline G16 & 15.2 & 77 & 106 & 75.2 & 18.9 & 1.2 & 17.3 & 24.5 & 25.3 \\
\hline G17 & 14.8 & 76 & 111 & 92.2 & 21.2 & 1.2 & 19.3 & 19.5 & 27.9 \\
\hline G18 & 19.3 & 74 & 116 & 95.5 & 25.1 & 1.4 & 19.6 & 13.7 & 35.2 \\
\hline G19 & 15.6 & 78 & 111 & 81.5 & 19.9 & 1.2 & 17.3 & 22.1 & 21.7 \\
\hline G20 & 15.7 & 75 & 110 & 83.6 & 17.9 & 1.1 & 17.2 & 30.1 & 21.1 \\
\hline G21 & 17.7 & 70 & 113 & 76.8 & 18.5 & 1.0 & 18.5 & 25.2 & 36.9 \\
\hline G22 & 17.6 & 79 & 112 & 71.2 & 20.3 & 1.2 & 16.7 & 18.3 & 26.1 \\
\hline G23 & 17.5 & 77 & 116 & 58.9 & 15.3 & 1.1 & 15.7 & 23.0 & 24.4 \\
\hline G24 & 12.9 & 89 & 115 & 77.6 & 20.0 & 1.5 & 18.2 & 13.0 & 32.7 \\
\hline G25 & 17.2 & 83 & 112 & 77.9 & 19.6 & 1.2 & 16.9 & 14.5 & 27.3 \\
\hline G26 & 18.9 & 81 & 114 & 93.2 & 26.5 & 1.3 & 21.0 & 11.5 & 29.8 \\
\hline G27 & 20.7 & 86 & 113 & 106.9 & 28.6 & 1.4 & 22.4 & 12.6 & 35.9 \\
\hline G28 & 16.9 & 87 & 111 & 76.2 & 18.4 & 1.3 & 16.0 & 24.0 & 37.5 \\
\hline G29 & 20.9 & 84 & 112 & 90.8 & 23.9 & 1.6 & 19.6 & 13.2 & 31.8 \\
\hline G30 & 13.5 & 80 & 117 & 76.5 & 21.5 & 1.4 & 18.5 & 21.5 & 19.6 \\
\hline G31 & 13.2 & 82 & 115 & 99.8 & 21.8 & 1.3 & 20.7 & 14.7 & 29.5 \\
\hline G32 & 15.8 & 89 & 117 & 87.6 & 20.2 & 1.1 & 18.2 & 37.3 & 17.8 \\
\hline G33 & 14.1 & 81 & 113 & 78.8 & 16.7 & 1.2 & 16.4 & 36.7 & 18.8 \\
\hline G34 & 14.1 & 83 & 113 & 79.9 & 17.3 & 1.2 & 17.9 & 34.0 & 19.8 \\
\hline G35 & 14.2 & 84 & 112 & 79.3 & 18.2 & 1.2 & 17.3 & 42.9 & 22.7 \\
\hline G36 & 17.8 & 79 & 120 & 92.3 & 27.2 & 1.3 & 18.8 & 28.6 & 24.8 \\
\hline G37 & 17.0 & 82 & 111 & 102.8 & 29.2 & 1.2 & 21.6 & 21.0 & 24.3 \\
\hline G38 & 21.5 & 90 & 117 & 89.0 & 25.9 & 1.3 & 20.5 & 16.8 & 30.9 \\
\hline G39 & 19.9 & 92 & 117 & 78.3 & 20.5 & 1.3 & 20.2 & 18.8 & 34.5 \\
\hline G40 & 19.4 & 96 & 116 & 88.5 & 24.8 & 1.2 & 19.7 & 18.6 & 21.1 \\
\hline G41 & 13.7 & 88 & 116 & 74.6 & 19.5 & 1.1 & 16.3 & 18.5 & 21.0 \\
\hline G42 & 23.5 & 93 & 115 & 76.8 & 22.8 & 1.4 & 16.5 & 19.8 & 36.6 \\
\hline G43 & 21.6 & 90 & 115 & 78.0 & 22.2 & 1.2 & 19.2 & 22.6 & 28.3 \\
\hline G44 & 15.8 & 81 & 115 & 101.3 & 22.9 & 1.5 & 19.7 & 33.1 & 39.1 \\
\hline G45 & 15.7 & 88 & 112 & 74.1 & 15.5 & 1.3 & 17.3 & 28.5 & 20.9 \\
\hline G46 & 14.7 & 89 & 113 & 77.9 & 26.9 & 1.3 & 17.1 & 28.5 & 21.7 \\
\hline G47 & 11.6 & 74 & 107 & 65.7 & 15.1 & 1.1 & 16.4 & 61.0 & 20.1 \\
\hline G48 & 13.5 & 88 & 117 & 105.3 & 24.2 & 1.4 & 18.9 & 18.9 & 34.4 \\
\hline
\end{tabular}

$\mathrm{TL}=$ number of effective tillers, $\mathrm{DH}=$ number of days to heading, $\mathrm{DM}=$ number of days to maturity, $\mathrm{PH}=$ plant height, FLL= flag leaf length, $\mathrm{FLW}=$ flag leaf width, $\mathrm{PL}=$ panicle length, $\mathrm{PB}=$ panicle blast and $\mathrm{GY}=$ grain yield (quintal ha-1) 
Table 4. Estimate of phenotypic and genotypic correlations of 48 rice genotypes evaluated at NaCRRI, Uganda in $2015 \mathrm{~A}$ and B cropping seasons

\begin{tabular}{|c|c|c|c|c|c|c|c|c|}
\hline \multirow{3}{*}{ DH } & & TL & DH & DM & PH & FLL & FLW & PL \\
\hline & $\mathrm{rp}$ & 0.212 & & & & & & \\
\hline & $\mathrm{rg}$ & 0.206 & & & & & & \\
\hline \multirow[t]{2}{*}{$\mathrm{DM}$} & $\mathrm{rp}$ & 0.24 & $0.491^{* * *}$ & & & & & \\
\hline & $\mathrm{rg}$ & 0.311 & $0.818^{* * *}$ & & & & & \\
\hline \multirow[t]{2}{*}{ PH } & $\mathrm{rp}$ & 0.168 & 0.253 & $0.356^{* * *}$ & & & & \\
\hline & $\mathrm{rg}$ & 0.233 & 0.255 & $0.385^{* *}$ & & & & \\
\hline \multirow[t]{2}{*}{ FLL } & $\mathrm{rp}$ & $0.357^{* *}$ & $0.434^{* * *}$ & $0.494^{* * *}$ & $0.763^{* * *}$ & & & \\
\hline & $\mathrm{rg}$ & 0.374 & $0.432^{* * *}$ & $0.736^{* * *}$ & $0.841^{* * *}$ & & & \\
\hline \multirow[t]{2}{*}{ FLW } & $\mathrm{rp}$ & 0.08 & $0.496^{* * *}$ & $0.427^{* *}$ & 0.519 *** & $0.563^{* * *}$ & & \\
\hline & $\mathrm{rg}$ & $0.189 *$ & $0.978^{* * *}$ & $0.970^{* * *}$ & $0.811^{* * *}$ & $0.947^{* * *}$ & & \\
\hline \multirow[t]{2}{*}{ PL } & rp & 0.259 & 0.248 & $0.406^{* *}$ & $0.778^{* * *}$ & $0.758^{* * *}$ & $0.433^{* *}$ & \\
\hline & $\mathrm{rg}$ & 0.287 & 0.256 & $0.492^{* * *}$ & $0.909^{* * *}$ & $0.895^{* * *}$ & $0.789^{* * *}$ & \\
\hline \multirow[t]{2}{*}{ GY } & $\mathrm{rp}$ & $0.473^{* * *}$ & -0.132 & 0.016 & 0.203 & 0.116 & 0.213 & 0.223 \\
\hline & $\mathrm{rg}$ & $0.589^{* * *}$ & -0.074 & 0.018 & $0.268^{*}$ & 0.173 & $0.6171^{* * *}$ & 0.292 \\
\hline
\end{tabular}

$\mathrm{rp}=$ phenotypic correlation coefficient and $\mathrm{rg}=$ genotypic correlation coefficient

Phenotypic and genotypic variances, expected genetic advance and heritability for grain yield and yield contributing traits of rice genotypes

The phenotypic coefficients of variation, genotypic coefficients of variations, variances, heritability in broad sense, genetic advance at $5 \%$ selection intensity and genetic advance as percent of the mean for all measured traits are presented in Table 5. The estimates of PCV and GCV indicated the existence of variability of genotypes included in the study. In general, the phenotypic coefficients of variations were higher than the genotypic coefficients of variations for all measured traits. The largest phenotypic variation was observed for grain yield (46.25\%) followed by number of effective tillers per hill (35.9\%), flag leaf length (35.7\%) and plant height (24.9 $\%)$. In line with this, the maximum genetic coefficient of variation was also recorded for grain yield (44.9\%) followed by flag leaf length $(35.2 \%)$ and number of effective tillers per hill (34.2\%).

Table 5. Phenotypic and genotypic variances, heritability and expected genetic advance of 48 lowland rice genotypes evaluated at NaCRRI over two cropping years

\begin{tabular}{lccccccc}
\hline Measured & \multicolumn{7}{c}{ Genetic parameters } \\
\cline { 2 - 8 } traits & GV $\left(\sigma^{2 \mathrm{~g}}\right)$ & $\mathrm{PV}\left(\sigma^{2 \mathrm{p}}\right)$ & $\mathrm{GCV}(\%)$ & $\mathrm{PCV}(\%)$ & $\mathrm{H}^{2}(\%)$ & GA $(\%)$ & GAM $(\%)$ \\
\hline TL & 34.19 & 37.73 & 34.22 & 35.95 & 0.91 & 11.48 & 67.19 \\
DH & 152.88 & 154.99 & 15.21 & 15.31 & 0.99 & 25.33 & 31.16 \\
DM & 28.40 & 40.66 & 4.70 & 5.62 & 0.70 & 9.19 & 8.10 \\
PH & 420.07 & 426.32 & 24.76 & 24.94 & 0.99 & 41.97 & 50.71 \\
FLL & 54.17 & 55.76 & 35.22 & 35.74 & 0.97 & 14.97 & 71.62 \\
FLW & 0.05 & 0.08 & 15.22 & 19.10 & 0.63 & 0.37 & 25.02 \\
PL & 10.52 & 11.27 & 17.70 & 18.31 & 0.93 & 6.47 & 35.28 \\
GY & 171.98 & 182.12 & 44.94 & 46.25 & 0.94 & 26.29 & 90.09
\end{tabular}

$\mathrm{GCV}=$ genetic coefficient of variation, $\mathrm{PCV}=$ phenotypic coefficient of variation, $\mathrm{H} 2=$ heritability in broad sense, GA=genetic advance at 5 $\%$ selection intensity, GAM=genetic advance as percent of the mean

Senapati and Kumar (2015), Suwansa et al. (2017), Biswaranjan et al. (2018), Nikki and Parmar (2020) had also reported high phenotypic and genetic coefficients of variation for grain yield per plant, number of panicles per plant, and number of spikelets per panicle. On the other hand, the smallest phenotypic (5.6\%) and genotypic coefficients of variations $(4.7 \%)$ were recorded on number of days to maturity and number of days to heading $15.3 \%$ and $15.2 \%$ respectively.

Estimation of the extent of heritability enables breeders to know the extent of which improvement is possible through selection. According to Burton (1952) genetic advance in combination with heritability gives a more reliable index for selection of traits than heritability alone. High degree of heritability was recorded for all measured traits in this study. It ranged from $63.0 \%$ for flag leaf width to $99.0 \%$ for number of days to heading. High heritability estimates associated with moderate to high genetic gain were observed for grain yield, plant height and flag leaf width. This indicated that the 


\section{Black Sea Journal of Agriculture}

influence of environments on the expression of this traits were low. Low genetic advance as percent of the mean coupled with low estimates of heritability were recorded for number of days to maturity, flag leaf width and number of days to heading, which indicated higher influence of environments on and hence, population improvement approach would be most effective for improvement of these characters that selection at early generation. As indicated in Table 5, the presence of sufficient variability in the studied traits showed high possibility to explore the material for further genetic improvement program.

\section{Conclusion}

The materials used in the study showed a highly significant difference for all measured traits and indicating the presence of substantial genetic variations and thus provide enough scope for selection. Among the tested genotypes SR33859-HB3324-133 (45.7 qha-1), SR33859-HB3324-93 (40.2 qha $^{-1}$ ) were the high yielding genotypes above the check and could be further evaluated in different locations and seasons before assuring for production. Moderate to a high degree of heritability estimates and high, GCV and PCV were found for grain yield, number of effective tillers per hill and flag leaf length which indicating the low or negligible influence of environment in the expression of this traits. The presence of sufficient variability in the studied traits, gives possibilities to explore the material for further genetic improvement program and also to widen the genetic background of various rice genotypes.

\section{Author Contributions}

All task made by single author and the author reviewed and approved the manuscript.

\section{Conflict of Interest}

The author declared that there is no conflict of interest.

\section{Acknowledgments}

I would like to thank Alliance for Green Revolution in Africa (AGRA) for the financial support and Ethiopian Institute of Agricultural Research for giving study leave. Fogera National Rice Research and Training Center (FNRRTC) had also acknowledged for hosting the author for his internship. The author had also grateful for the National Crop Research Resources Institute (NaCRRI) of Uganda, especially rice research programme for hosting the research activity.

\section{References}

Akongo GO, Gombya-Ssembajjwe W, Buyinza M, Namaalwa J. 2017. Characterization of rice production systems in Northern Agro-Ecological Zone, Uganda. J Agri Sci, 10(1): 272-282.

Biswaranjan B, Simanchal S, Rajesh K, Ritu K. 2018. Studies on genetic variability for some metric traits in slender grain rice genotypes. J Applied Nat Sci, 10(1): 375-378.

Burton GW. 1952. Quantitative inheritance in grasses. In Proceedings of the Sixth International Grassland Congress, August 17-23, Pennsylvania State College, State College, Pennsylvania, USA, (1), 277-283.

Dogara AM, Jumare AI. 2014. Origin, distribution, and heading date in cultivated rice. Int J Plant Biol Res, 2: 2-6.

FAO. 2018. Food and agriculture organization of the united nations statistics division. URL: https://www.fao.org/home/en (accessed date: March 23, 2020).

Haggblade S, Dewina R. 2010. Staple food price in Uganda. URL: https://core.ac.uk/download/pdf/6449502.pdf (accessed date: March 23, 2020).

Johnson HW, Robinson HF, Comstock RE. 1955. Estimates of genetic and environmental variability in soybean. Agron J, 47: 314-318.

Kijima Y, Sserunkuuma D. 2006. The adoption of NERICA rice varieties at the initial stage of the diffusion process in Uganda. African J Agric Res Econ, 8: 1-11.

Kijima, Y. 2012. Expansion of lowland rice production and constraints on a rice green revolution. JICA-RI working paper, No. 49, URL: https://www.jica.go.jp/jicari/publication/workingpaper/post.html (accessed date: March 23, 2020).

Nikki K, Parmar M. 2020. Heritability and genetic advance analysis in rice (Oryza sativa L.) genotype under aerobic condition. Int J Curr Microbiol App Sci, 9(3): 1196-1204.

Payne RW, Murray DA, Harding SA, Baird DB, Soutar DM. 2009. An introduction to GenStat for Windows. VSN International, 5. The Waterhouse, Waterhouse Street, Hemel Hempstead, London, UK $12^{\text {th }}$ ed., pp. 287.

Senapati BK, Kumar A. 2015. Genetic assessment of some phenotypic variants of rice (Oryza spp.) for some quantitative characters under the genetic plains of West Bengal. African J Biotechnol, 14(3): 187-201.

Seyoum M, Alamerew S, Bantte K. 2012. Genetic variability, heritability, correlation coefficient, and path analysis for yield and yield-related traits in upland rice (Oryza sativa L.). J Plant Sci, 7(1): 13-22.

Sravan T, Rangare NR, Suresh BG, Kumar SR. 2012. Genetic variability and character association in rainfed upland rice (Oryza sativa L.) J Rice Res, 5(1-2): 24-28.

Suwansa C, Charassri N, Nattapon J, Watcharin S. 2017. Genetic diversity, genetic variability, and path analysis for yield and its components in indigenous upland rice (Oryza sativa L. var. glutinosa). Songklanakarin J Sci Technol, 40(3): 609-616. 